\title{
Assessment of the prevalence of Soil Transmitted Helminthiasis in Bangladesh
}

\author{
DR. HASINA NASREEN, MD ${ }^{*}$ \\ DR. JAHIRUL KARIM, MD² \\ DR. MUJIBUR RAHMAN ${ }^{3}$ \\ DR. ANAND JOSHI ${ }^{4}$ \\ ${ }^{1}$ Deputy Director, Planning and Development, Chattogram Medical University, Bangladesh \\ ${ }^{2}$ Deputy Program Manager, Filariasis and STH Control Program, DG Health, Dhaka, Bangladesh \\ ${ }^{3,4}$ Consultant, Filariasis and STH Control Program, DG Health, Dhaka, Bangladesh
}

*(hasinanasreen2018@gmail.com)

This journal is licensed under a Creative Commons Attribution-NonCommercial 4.0 International License (CC-BY-NC). Articles can be read and shared for noncommercial purposes under the following conditions:

- BY: Attribution must be given to the original source (Attribution)

- NC: Works may not be used for commercial purposes (Noncommercial)

This license lets others remix, tweak, and build upon your work non-commercially, and although their new works must also acknowledge you and be non-commercial, they don't have to license their derivative works on the same terms. License Deed Link: http://creativecommons.org/licenses/by-nc/4.0/ Legal Code Link: http://creativecommons.org/licenses/by-nc/4.0/legalcode $A B C$ Research Alert uses the CC BY-NC to protect the author's work from misuse.

\begin{abstract}
Intestinal worm infestation is a global health problem. Soil-transmitted Helminths (STH) infects nearly 2 billion people of world's population with children being the most affected. STH infections rarely cause mortality with diarrhea, abdominal pain and low hemoglobin levels as the immediate outcome of infections, however, the long term effects of these infections are far more sinister as those with infections show reduced cognitive abilities, intellectual capacity and lower work productivity. Due to the subtropical monsoonal climate and being a least developed country, Bangladesh is endemic for helminthes infection especially for STH. There are a very few studies conducted on STH infection in Bangladesh. In March 2017, the Program implemented STH monitoring surveys in Nilphamari districts. Trained medical technologists conducted laboratory testing of stool samples using the Kato-Katz method. Survey teams collected hygiene, sanitation, and preventive drug treatment-related information using standardized questionnaires administered during household visits. Firstly, provide statistically valid, district-level estimates of STH prevalence and intensity of infection that are specific to, and representative of key STH at-risk age groups. Secondly, assess potential factors affecting STH infection rates including recent preventive chemotherapy coverage, sanitation coverage, and specific hygiene-related behaviors. STH control activities are more diffuse, aiming to piggy-back de-worming onto existing services such as school health activities; controlling morbidity, rather than eliminating infection, is the stated goal.
\end{abstract}

Keywords

Prevalence; STH; whipworm; hookworm; roundworm.

\section{INTRODUCTION}

Soil-transmitted Helminths (STH) infects nearly 2 billion people of world's population with children being the most affected (Savioli, 2004). According to the World Health Organization 
(WHO) estimates, 870 million children live in the area of high prevalence. Africa, South Asia and South America are the most affected regions of the world (Lobo, 2011). STH infections rarely cause mortality with diarrhea, abdominal pain and low hemoglobin levels as the immediate outcome of infections, however, the long term effects of these infections are far more sinister as those with infections show reduced cognitive abilities, intellectual capacity and lower work productivity (Bethony, 2006). The warm and moist climate of tropical and subtropical countries provides the ideal environment for the survival of parasite eggs or larvae of these four STH, roundworm (Ascaris lumbricoides), whipworm (Trichuris trichiura) and hookworm (Necator americanus, Ancylostoma duodenale) (Clements, 2006). They are among the most common infections worldwide which heavily affect the poorest and most deprived communities where the sanitation is inadequate and water supplies unsafe (WHO, 2001-2010).

Soil transmitted helminthes (STH) are one of the most common neglected tropical diseases (NTD). STHs mainly cause nutritional imbalances the different infections affect humans at different times of their life. Commonly, they cause a decreased appetite leading to reduced food intake, lethargy, impaired digestion and absorption of nutrients from the diet and thereby poor growth and development of children. Some, like hookworms, are primarily responsible for blood loss leading to iron deficiency and iron deficiency anemia leading decreased working capacity of adults and impaired neurocognitive development of young children (WHO, 2014).

Due to the subtropical monsoonal climate and being a least developed country, Bangladesh is endemic for helminthes infection especially for STH. Poor housing conditions, overcrowding, scarcity of safe drinking water and lack of proper hygiene and sanitation are common factors that contribute to the increased prevalence of these parasites in this country. There are a very few studies conducted on STH infection in Bangladesh. Data regarding survey on STH are also not traceable even after thorough search. The study could contribute to the planning and implementation of effective helminthes prevention and control measures.

\section{MATERIALS AND METHODS}

In March 2017, the Program implemented STH monitoring surveys in Nilphamari districts. Trained medical technologists conducted laboratory testing of stool samples using the Kato-Katz method. Survey teams collected hygiene, sanitation, and preventive drug treatment-related information using standardized questionnaires administered during household visits.

The Integrated Community-based Survey for STH Program Monitoring (ICSPM) is a population-based, cross-sectional cluster survey to monitor the STH prevalence and intensity of infection which uses the district as the evaluation unit. Survey teams randomly selected 30 clusters. A random sampling interval was applied to households within each cluster to select the survey population. The ICSPM collects statistically valid data for three STH risk groups:

1) Preschool age children (PSAC): 1-4 years old

2) School age children (SAC): 5-14 years old

3) Adults (>14 years old) (for this survey only we consider above 14 years as adults population)

The following report provides key results from the ICSPM in Nilphamari. The report seeks to summarize key data on STH prevalence, intensity of infections, personal hygiene, sanitation and environmental aspect to inform ongoing Program and partner activities. 


\section{Statistical Analysis}

After completion of collection, the obtained data was checked, verified, edited and coded. All the data was recorded in a computerized structured form. A single form was allocated for a single patient. After registering the personal information examination findings and investigation findings of the patients each form was saved as a distinct file in a definite folder of a specific computer. After achieving the target number of patient within the study time they obtained data were analyzed and statistical evaluation was performed by SPSS-21 program.

\section{RESULTS AND DISCUSSION}

\begin{tabular}{|cc|}
\hline & $\mathrm{n}(\%)$ \\
\hline \hline \multicolumn{1}{|c|}{ Enrolled } & $n=1,616$ \\
\hline PSAC (1-4 yrs) & $274(17.0)$ \\
SAC (5-14 yrs) & $451(27.9)$ \\
Adult (>14 yrs) & $891(55.1)$ \\
\hline Provided Sample & $n=966$ \\
\hline PSAC (1-4 yrs) & $152(15.7)$ \\
SAC (5-14 yrs) & $281(29.1)$ \\
Adult (>14 yrs) & $533(55.2)$ \\
\hline
\end{tabular}

Table 1. Enrollment and sampling rates

Preschool-age children and school-age children were under-represented in the study population. Non-compliance was consistent (and higher than expected) across age groups.

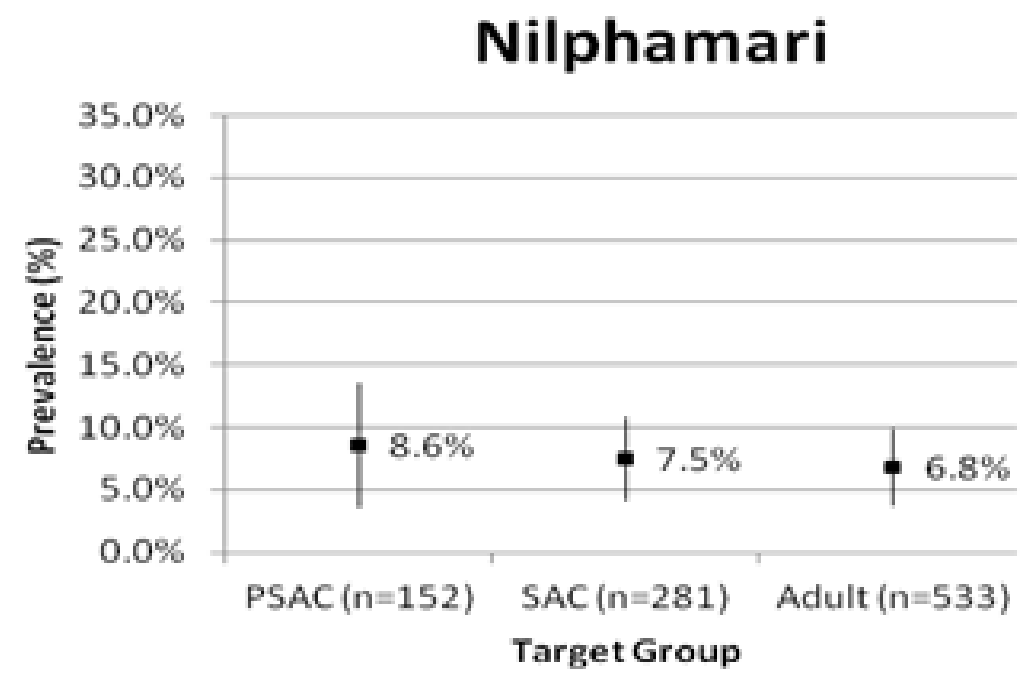

Figure 1. STH Prevalence (95\% CI)

Prevalence of infection with STH species is substantial. 


\begin{tabular}{|rccc|}
\hline Parasite & $\begin{array}{c}\text { Light intensity } \\
\text { infection }\end{array}$ & $\begin{array}{c}\text { Moderate intensity } \\
\text { infection }\end{array}$ & $\begin{array}{c}\text { Heavy intensity } \\
\text { infection }\end{array}$ \\
\hline \hline Ascaris & $<5000$ & $\geq 5,000-50,000$ & $>50,000$ \\
Trichuris & $<1,000$ & $\geq 1,000-10,000$ & $>10,000$ \\
Hookworm & $<2,000$ & $\geq 2,000-4,000$ & $>4,000$ \\
\hline
\end{tabular}

Table 2: WHO Classification of STH infection Intensity (eggs per gram of stool)

Nilphamari

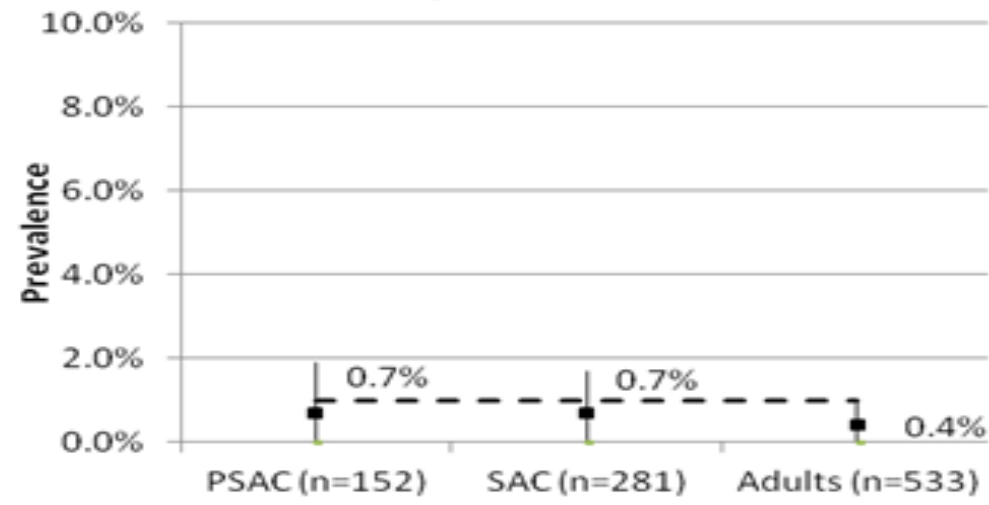

Figure 2. STH of moderate-to-high intensity (MHI) infection prevalence (95\% CI) \& WHO MHI goal

STH remains a public health problem in PSAC and SAC with a prevalence rates are same (Figure 2).

\begin{tabular}{|c|c|c|c|c|c|c|}
\hline & \multicolumn{3}{|c|}{$\begin{array}{c}\text { Prevalence }(\%) \\
{[95 \% \mathrm{CI}]}\end{array}$} & \multicolumn{3}{|c|}{$\begin{array}{l}\text { MHI (\%) } \\
{[95 \% \mathrm{CI}]}\end{array}$} \\
\hline & $P S A C$ & $S A C$ & Adult & PSAC & $S A C$ & Adult \\
\hline Nilphamari & $n=152$ & $\mathrm{n}=281$ & $\mathrm{n}=533$ & $n=149$ & $n=243$ & $n=535$ \\
\hline Dimla $(n=120)$ & $\begin{array}{c}9.5 \\
{[0-34.6]}\end{array}$ & $\begin{array}{c}6.5 \\
{[0-18.2]}\end{array}$ & $\begin{array}{c}11.8 \\
{[0-36.5]}\end{array}$ & $\begin{array}{c}4.8 \\
{[0-17.3]}\end{array}$ & $\begin{array}{c}3.2 \\
{[0-14.3]}\end{array}$ & $\begin{array}{c}2.9 \\
{[0-8.4]}\end{array}$ \\
\hline $\operatorname{Domar}(\mathrm{n}=171)$ & $\begin{array}{c}5.6 \\
{[0-22.7]}\end{array}$ & $\begin{array}{c}10.5 \\
{[0-23.6]}\end{array}$ & $\begin{array}{c}4.3 \\
{[0-8.9]}\end{array}$ & 0.0 & 0.0 & 0.0 \\
\hline Jaldhaka $(\mathrm{n}=153)$ & $\begin{array}{c}7.7 \\
{[0-18.1]}\end{array}$ & $\begin{array}{c}1.9 \\
{\left[\begin{array}{l}0 \\
-6.7]\end{array}\right.}\end{array}$ & $\begin{array}{c}5.3 \\
{[0-14.3]}\end{array}$ & 0.0 & 0.0 & 0.0 \\
\hline Kishoregonj $(\mathrm{n}=155)$ & 0.0 & $\begin{array}{c}6.1 \\
{[1.8-10.5]}\end{array}$ & $\begin{array}{c}3.8 \\
{[0.1-7.7]}\end{array}$ & 0.0 & 0.0 & 0.0 \\
\hline $\begin{array}{r}\text { Nilphamari Sadar }(\mathrm{n}= \\
228)\end{array}$ & $\begin{array}{c}10.5 \\
{[0-25.7]}\end{array}$ & $\begin{array}{c}6.0 \\
{[0-12.6]}\end{array}$ & $\begin{array}{c}4.1 \\
{[0-10.0]}\end{array}$ & 0.0 & $\begin{array}{c}1.5 \\
{[0-5.0]}\end{array}$ & 0.0 \\
\hline Sayedpur $(\mathrm{n}=139)$ & $\begin{array}{c}19.0 \\
{[0-43.4]}\end{array}$ & $\begin{array}{c}15.9 \\
{[0-36.7]}\end{array}$ & $\begin{array}{c}14.9 \\
{[0.2-29.5]}\end{array}$ & 0.0 & 0.0 & 0.0 \\
\hline TOTAL & $\begin{array}{c}8.6 \\
{[3.6-13.5[} \\
\end{array}$ & $\begin{array}{c}7.5 \\
{[4.2-10.8]}\end{array}$ & $\begin{array}{c}6.8 \\
{[3.7-9.8]} \\
\end{array}$ & $\begin{array}{c}0.7 \\
{[0-2.0]}\end{array}$ & $\begin{array}{c}0.7 \\
{[0-1.7]}\end{array}$ & $\begin{array}{c}0.4 \\
{[0-0.9]}\end{array}$ \\
\hline
\end{tabular}

Table 3. Prevalence with $[95 \% \mathrm{CI}]$ \& MHI any STH by sub-district 
The geographic distribution of disease is not uniform across, showing geographic clustering. In Nilphamari, STH prevalence and MHI are concentrated in Dimla upazilla (Table 3). In Sayedpur Upazila, limited to no MHI detected but prevalence as high as $36.7 \%$ in SAC (Table 3).

\begin{tabular}{|c|c|c|c|}
\hline & $\begin{array}{c}\text { PSAC } \\
\mathrm{N}=152 \\
\%(95 \% \mathrm{CI})\end{array}$ & $\begin{array}{c}\underline{\mathbf{S A C}} \\
\mathrm{N}=281 \\
\%(95 \% \mathrm{CI})\end{array}$ & $\begin{array}{c}\text { Adult } \\
\mathrm{N}=533 \\
\%(95 \% \mathrm{CI})\end{array}$ \\
\hline Received $\leq 6$ months ago & $\begin{array}{c}21.2 \% \\
{[10.6-31.8]}\end{array}$ & $\begin{array}{c}56.6 \% \\
{[44.3-68.8]}\end{array}$ & $\begin{array}{c}14.9 \% \\
{[7.0-22.7]}\end{array}$ \\
\hline Most common source of $P C$ & Purchased & School & Purchased \\
\hline $\begin{array}{l}\% \text { receiving via most com- } \\
\text { mon form in last* }\end{array}$ & $\begin{array}{c}56.0 \% \\
{[39.8-72.3]}\end{array}$ & $\begin{array}{c}87.3 \% \\
{[78.5-96.2]}\end{array}$ & $\begin{array}{c}44.4 \% \\
{[27.9-60.8]}\end{array}$ \\
\hline
\end{tabular}

Preventive chemotherapy coverage for SAC was only $56.6 \%$.

Table 4. STH Preventive Chemotherapy coverage by age group.

\begin{tabular}{|c|c|c|c|c|}
\hline & $\begin{array}{c}\text { Hand washing } \\
\text { station w/soap, } \\
\text { home } \\
\%\end{array}$ & $\begin{array}{c}\text { Improved } \\
\text { sanitation, }^{\wedge} \\
\text { home } \\
\% \\
\end{array}$ & $\begin{array}{c}\text { Improved } \\
\text { sanitation, } \\
\text { work } / \text { school } \\
\% \\
\end{array}$ & $\begin{array}{c}\text { Improved } \\
\text { flooring }^{\wedge \wedge} \\
\% \\
\end{array}$ \\
\hline \multicolumn{5}{|l|}{ Nilphamari $(n=966)$} \\
\hline $\operatorname{Dimla}(\%)(\mathrm{n}=120)$ & 13.3 & 80.8 & 77.5 & 15.8 \\
\hline $\operatorname{Domar}(\mathrm{n}=171)$ & 16.4 & 95.3 & 89.5 & 16.4 \\
\hline Jaldhaka $(\mathrm{n}=153)$ & 23.5 & 97.4 & 97.4 & 4.6 \\
\hline Kishoregonj $(n=155)$ & 7.7 & 60.6 & 60.0 & 12.9 \\
\hline Nilphamari Sadar $(n=228)$ & 15.4 & 94.3 & 82.9 & 14.9 \\
\hline Sayedpur $(n=139)$ & 25.2 & 82.0 & 46.8 & 20.1 \\
\hline TOTAL & 16.8 & 86.1 & 76.8 & 14.1 \\
\hline
\end{tabular}

Table 5. Point estimates of household WASH coverage indicators

${ }^{\wedge}$ Improved sanitation - flush toilet to sewer/septic; ventilated improved pit latrine; pit latrine w/ slab; composting toilet

$\wedge \wedge$ Improved flooring - bamboo; floor planks; brick; cement

In Syedpur Upazila, only $25.2 \%$ of people have a hand washing station with soap at home and $46.8 \%$ have improved sanitation at work/school.

\section{DISCUSSION}

Intestinal worm infestation is a global health problem and is a matter of serious concern for the third world countries. Overcrowding, contamination of water, poor sanitation and migration of people to cities greatly favour transmission of parasitic infection resulting in high endemicity. 
STH infections form the most important group of intestinal worms and account for $27 \%$ of entire school-age and preschool-age children population in the World, who are in need of anthelminthic treatment (WHO, 2012). Preschool-age children and school-age children were under-represented in the study population (Table 1). Non-compliance was consistent (and higher than expected) across age groups. Prevalence of infection with STH species is substantial (Figure 1). STH remains a public health problem in PSAC and SAC with a prevalence rate is 0.7 (Figure 2). The geographic distribution of disease is not uniform across, showing geographic clustering. In Nilphamari, STH prevalence and MHI are concentrated in Dimla upazilla. In Sayedpur Upazila, limited to no MHI detected but prevalence as high as $36.7 \%$ in SAC (Table 3). Preventive chemotherapy coverage for SAC was only $56.6 \%$ (Table 4). In Syedpur Upazila, only $25.2 \%$ of people have a hand washing station with soap at home and $46.8 \%$ have improved sanitation at work/school. (Table 5).

\section{CONCLUSION}

Analyzing the results we can conclude that the prevalence of STH infections remain high among children and pose an important public health problem in Bangladesh. Our effort is expected to provide an appropriate epidemiological basis for guiding investments in helminthes control and de-worming activities across the country. Proper health and sanitation education, periodic chemotherapy with anti-helminthes, cooperation with school, various organizations and community should be prioritized as the effective helminthes infection prevention and control measures.

\section{References}

Bethony J, Brooker S, Albonico M, Geiger SM, Loukas A, et al. (2006). Soil-transmitted helminth infections: ascariasis, trichuriasis, and hookworm. Lancet. 367:1521-32.

Clements AC, Bundy DA. (2006). Global epidemiology, ecology and control of soil-transmitted helminth infections. Adv Parasitol. Brooker 62:221-61.

Lobo DA, Velayudhan R, Chatterjee P, Kohli H, Hotez PJ. (2011). The neglected tropical diseases of India and South Asia: review of their prevalence, distribution, and control or elimination. PLoS Negl Trop Dis. 5:e1222.

Savioli L, Albonico M. (2004). Soil-transmitted helminthiasis. Nat Rev Microbiol. 2:618-9.

WHO. (2001-2010) Eliminating soil-transmitted helminthiases as a public health problem in children: progress report 2001-2010 and strategic plan 2011-2020.WHO Press, Geneva (World Health Organisation).

WHO. (2014). Use of improved drinking water sources. Global Health Observatory. Available from: http://www.who.int/gho/mdg/environmental_sustainability/water/en.

WHO. (Geneva: 2012). Soil-transmitted Helminthiases. Eliminating Soil-transmitted Helminthiasis as a Public Health Problem in Children: Progress Report 2001-2010 and Strategic Plan 2011-2020; pp. 3-4 